\title{
Radiation Dose Enhancement in Megavoltage Radiation Therapy using Au, Gd, Pt, Ag, and Bi Nanoparticles of Various Concentration Level
}

\author{
Fouad Abolaban 1,* (D), Andrew Nisbet 2 (iD \\ 1 King Abdulaziz University, College of Engineering, Nuclear Engineering Department, Jeddah, Kingdom of Saudi Arabia, \\ Jeddah 21589, Saudi Arabia; fabolaban@kau.edu.sa (F.A.); \\ 2 Department of Medical Physics \& Biomedical Engineering, University College London, Malet Place Engineering Building, \\ London WC1E 6BT, UK; andrew.nisbet@ucl.ac.uk (A.N.); \\ Correspondence: fabolaban@kau.edu.sa (F.A.);
}

Scopus Author ID 14041116800

Received: 23.04.2021; Revised: 25.05.2021; Accepted: 28.05.2021; Published: 18.06.2021

\begin{abstract}
A digital phantom was created from a CT scan of a patient's head and employed together with GATE 8.2 Monte Carlo modeling of a linear accelerator of nominal $6 \mathrm{MV}$ energy to simulate an irradiation geometry for a typical tumor volume centrally within the brain region. Although simplistic in arrangement, this setup was considered appropriate to demonstrate the dose enhancements that may be expected for megavoltage external beam radiation therapy for nanoparticles (NP) of different elemental composition and concentration. $\mathrm{Ag}, \mathrm{Gd}, \mathrm{Pt}, \mathrm{Au}$ and Bi were modeled in concentrations varying from $15 \mathrm{mg} \mathrm{NP} /$ gram tissue to $70 \mathrm{mg}$ NP / gram tissue. The maximum Average Dose Enhancement Factor (ADEF) to the Gross Tumour Volume (GTV) observed was $3 \%$ for $70 \mathrm{mg}$ NP / gram tissue of Bi.
\end{abstract}

Keywords: dose enhancement; GATE Monte Carlo; nanoparticles; dosimetry.

(C) 2021 by the authors. This article is an open-access article distributed under the terms and conditions of the Creative Commons Attribution (CC BY) license (https://creativecommons.org/licenses/by/4.0/).

\section{Introduction}

Radiotherapy is the treatment of disease, predominantly cancer, with ionizing radiation and is employed in approximately $50 \%$ of cancer treatments [1]. The essential aim of radiotherapy is to maximize the radiation dose to the target, i.e., the tumor and surrounding margins, whilst minimizing the radiation dose to the normal tissues and organs at risk, thus increasing the therapeutic index [2].

Over the last two decades, technological advancements, such as image-guided radiotherapy [3] and intensity-modulated radiotherapy [4], have seen significant advancements in this area. Recently, the use of nanoparticles in radiotherapy has received much attention as another means to increase radiotherapeutic efficacy. This arises due to the enhanced permeability and retention (EPR) effect, the preferential accumulation of nanoparticles in the tumor, which may result in an increased local dose of radiation within the tumor due to a greater probability of radiation interaction when irradiated [5-7].

Several studies have reported on this dose enhancement both in vitro (e.g. [8], [9], ) and in an animal in vivo studies (e.g. [10-13]). The majority of such studies have involved the study of gold nanoparticles in the kilovoltage $x$-ray energy range, where this increased dose arises due to the photoelectric cross-section of high atomic numbers $\mathrm{Z}$ elements, which varies as $\mathrm{Z}^{\mathrm{n}} / \mathrm{E}^{3}$, where $E$ is the energy of the interacting photon and $4<\mathrm{n}<5[10,11]$. However, it has become 
clear that the increased radiosensitivity reported results from a combination of the physical dose enhancement and additional chemical and biological effects associated with the nanoparticle in use $[6,12,13]$. Despite this body of work and the availability of commercial nanoparticles, the clinical translation of nanoparticles has been limited [14,15], although reports from clinical trials are beginning to emerge [16-18]. Gold has been the predominant nanoparticle studied to date due to its high x-ray absorption coefficient at kilovoltage energies and the ability to manufacture the nanoparticles' size, shape and surface properties to optimize particle stability, solubility and biological properties. However, other nanoparticles have also been studied to varying degrees, including gadolinium and titanium oxide nanotubes [19-21].

To facilitate the clinical translation of nanoparticles, it is important to be able to quantify each of the contributory factors, i.e., the physical dose enhancement and the chemical and biological effects [22,23]. In particular, studies at the more clinically useful Megavoltage x-ray energy range are limited, particularly for nanoparticles other than gold. Taha et al. (2019) [24] have recently summarized some issues to consider for clinical translation, including the radiation species emitted by the nanoparticles and local energy deposition, which may influence the biological effect, and the effect of the nanoparticles' surface coating. They subsequently investigated the dose enhancement of silver nanoparticles implanted in the brain for brachytherapy treatment [25-27].

In this work, we employ a Monte Carlo model of a linear accelerator, with a realistic digital phantom produced from an anonymized patient CT scan, and a simple yet realistic parallel pair treatment delivery technique to determine the dose enhancement arising from Silver, gadolinium, platinum gold and bismuth-based nanoparticles employed with nominal 6MV Megavoltage external beam radiotherapy. An assessment of the effect of varying concentrations of such nanoparticles is also determined. Such a model enables an initial assessment of possible nanoparticle base elements to optimize the composition and design of nanoparticles from a physical dose enhancement perspective. Further studies increasing the complexity of radiation therapy delivery techniques may also be incorporated using such a model. Such studies at the most relevant clinical external beam radiation therapy modalities are essential to ensure sufficient preclinical evidence is available for future clinical study design.
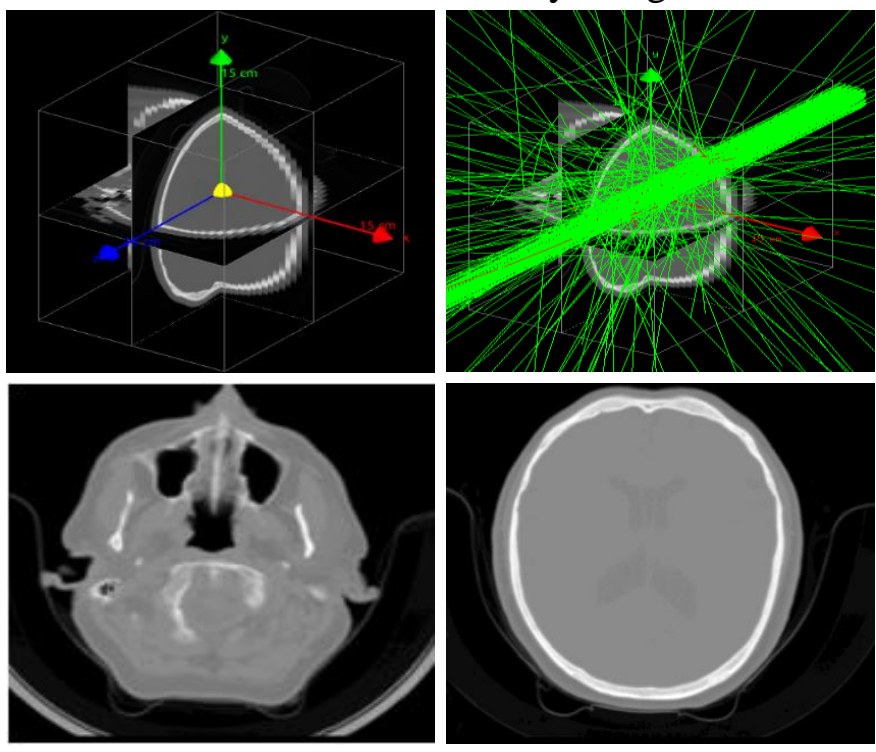

Figure 1. Illustration of Digital phantom with one lateral beam dose distribution. Top left: central sphere $2 \mathrm{~cm}$ diameter tumor. Top right: one lateral beam and demonstration of scattered radiation and dose distribution. Lower left: CT slice number 32 of the digital phantom. Lower right: CT slice number 16 of the digital phantom. 


\section{Materials and methods}

Employing a similar methodology described by Taha et al. [24], a digital phantom was developed based upon a 512 x 512 x 32 voxel brain CT scan (Figure 1). The Monte Carlo code GATE [28] was then employed to enable external beam irradiation conditions to be modeled from a clinical linear accelerator and accurate dose distributions to be determined.

A "dose ACTOR" tool in GATE was used in this investigation to record the dose distribution in the digital phantom. The Monte-Carlo simulation was run on a virtual Ubuntu 16.04 LTS produced by Canonical Ltd, running on an i7-4770 3.4 GHz Intel processor and 24 GB RAM.

A spherical tumor volume with a $2 \mathrm{~cm}$ diameter was placed at the center of the digital phantom. All nanoparticles are added to the tumor as a part of its mixture composition to be homogeneously distributed. The tumor composition was defined to consist of oxygen, carbon, hydrogen and nitrogen with concentrations of $73.77 \%, 12.54 \%, 11 \%$, and $1.32 \%$, respectively. The remaining $1.37 \%$ divided between Sodium, Phosphorus, Sulfur, Potassium, Chloride, Calcium and Scandium with less than $0.2 \%$ concentration each.

Introducing the NPs to the phantom as volumes with size and shape is considered a more accurate technique in simulating NPs. The main drawback of this technique is that it requires creating a large number of volumes $\left(10^{12}\right.$ in some cases), which lengthens the computation time significantly and increases the memory requirements. In the technique employed in this study, NPs were added to the volume composition mixture. This technique may overestimate the DEF, however, this potential overestimation is minimal compared to the increased computational efficiency.

A realistic yet simple beam arrangement of two lateral beams of nominal $6 \mathrm{MV}$ energy with a field size of $2.2 \times 2.2 \mathrm{~cm}^{2}$ was directed to the tumor. Five different nanoparticles (NPs) that have previously been reported as used within the literature [29] were virtually embedded within the tumor. The nanoparticles being Ag-Silver, Gd-Gadolinium, Pt-Platinum, Au-Gold, and BiBismuth (see Table 1). Four different concentrations were examined, namely 15, 25, 35 and 70 mg of NP per gram of tumor tissue. Dose Enhancement Factor (DEF) values were obtained for all 5 NPs at each of the four concentrations.

Table 1. Atomic number and electronic density for elements used in this study.

\begin{tabular}{c|c|c|c} 
Element & $\begin{array}{c}\text { Atomic } \\
\text { Number }\end{array}$ & $\begin{array}{c}\text { Effective Atomic Number for 70 } \\
\text { mg/g NPs in soft tissue }\end{array}$ & $\begin{array}{c}\text { Electron density } \\
\text { (electrons/gram) } \times \mathbf{1 0}^{\mathbf{2 4}}\end{array}$ \\
\hline $\mathrm{Ag}$ & 47 & 46 & 2.77 \\
\hline $\mathrm{Gd}$ & 64 & 62 & 2.00 \\
\hline $\mathrm{Pt}$ & 78 & 76 & 5.17 \\
\hline $\mathrm{Au}$ & 79 & 77 & 4.67 \\
\hline $\mathrm{Bi}$ & 82 & 81 & 2.34
\end{tabular}

The dose distribution within the digital phantom was obtained by dividing it into $512 \mathrm{x}$ $512 \times 32$ voxels, with four types of dose information recorded in each voxel (Voxel size $=0.43 \mathrm{x}$ $0.43 \times 5 \mathrm{~mm}^{3}$ ). These being the total dose, the primary radiation dose, the secondary radiation dose and the uncertainty. The uncertainty was kept below $5 \%$ in all regions of interest by simulating $5 \times 10^{8}$ photons in each run. Additionally, two types of DEFs were measured in the tumor volume: the average dose enhancement factor (ADEF) and the maximum dose enhancement factor (MDEF). The major difference between the MDEF and ADEF lies mainly in the latter being heavily affected by the tumor size, as the DEF decreases with depth, reducing the ADEF [24]. The MDEF and ADEF were calculated in three clinically relevant treatment volumes, the Gross Tumor Volume (GTV) with $2 \mathrm{~cm}$ diameter, the Irradiated Tumor Volume (ITV) with 
$2.1 \mathrm{~cm}$ diameter and the Planning Target Volume (PTV) with $2.15 \mathrm{~cm}$ diameter (see Figure 2) [30]. The calculations of the DEFs were carried out using a MATLAB developed script. The DEF is estimated by dividing the accumulated dose distribution in the relevant volume in the presence of NPs by the accumulated dose distribution in the relevant volume without NPs. Binary masks were used to isolate the regions of interest from the rest of the image. This approach ensures a more accurate delineation of both the tumor and healthy tissue volumes, where the regions of interest retain their dose values while the remaining voxels are zeroed and eliminated from MDEF and ADEF calculations.

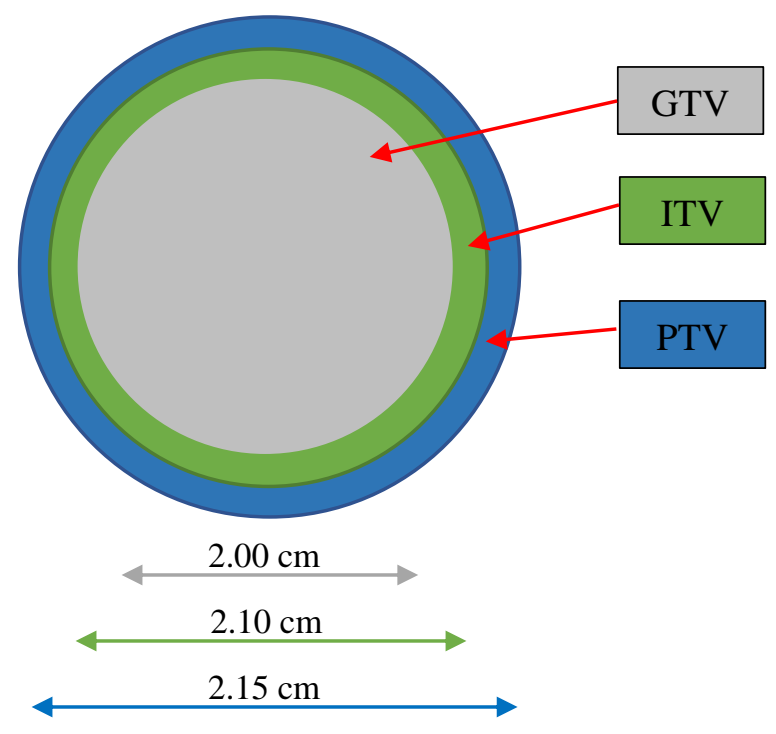

Figure 2. Areas of dose enhancement measurements surrounding the Gross Tumor Volume (GTV) of $2 \mathrm{~cm}$ diameter. Irradiated Tumor Volume (ITV) of $2.1 \mathrm{~cm}$ diameter and the Planning Target Volume (PTV) of $2.15 \mathrm{~cm}$ diameter.

\section{Results and Discussion}

Figure 3 illustrates the beam arrangement and dose maps for each nanoparticle type. Figure 4 illustrates the dose map from each radiation field individually and the total dose from the combined beam arrangement. In table 2 the dose enhancement in the GTV is tabulated for each nanoparticle type and concentration. The increase in ADEF increases from $1 \%$ to $3 \%$ for bismuth from $15 \mathrm{mg} / \mathrm{gram}$ to $70 \mathrm{mg} / \mathrm{gram}$. For Au this increase is from $0 \%$ to $3 \%$, for Pt $0 \%$ to $2 \%$ and $\mathrm{Gd}$ $0 \%$ to $1 \%$. Au shows no dose enhancement. There is some localized dose enhancement as shown by the MDEF values, which show increases up to $10 \%$ for $\mathrm{Bi}$ at the highest concentrations. However, to ensure full tumor control, the ADEF is likely to be more clinically relevant.

Table 3 tabulates the ADEF and MDEF values for the ITV, which encompasses an area surrounding the tumor where no NPs are embedded. This is an idealized clinical situation assuming the ideal specificity of uptake within the tumor. For this situation, the increase in ADEF increases from $0 \%$ to $2 \%$ for bismuth from $15 \mathrm{mg} / \mathrm{gram}$ to $70 \mathrm{mg} / \mathrm{gram}$. For Au this increase is from $0 \%$ to $2 \%$, for Pt $0 \%$ to $2 \%$ and $\mathrm{Gd} 0 \%$ to $1 \%$. Au again shows no dose enhancement. Again, there is some localized dose enhancement as shown by the MDEF values, which show increases up to $10 \%$ for $\mathrm{Bi}$ at the highest concentrations

Table 4 tabulates the ADEF and MDEF values for the PTV, which encompasses a larger area surrounding the tumor where no NPs are embedded. Again this is an idealized clinical situation assuming ideal specificity of uptake within the tumor. For this situation, the increase in ADEF increases from $1 \%$ to $3 \%$ for bismuth from $15 \mathrm{mg} / \mathrm{gram}$ to $70 \mathrm{mg} / \mathrm{gram}$. 
NPs

Type

$\mathrm{Au}$

$\mathrm{Ag}$
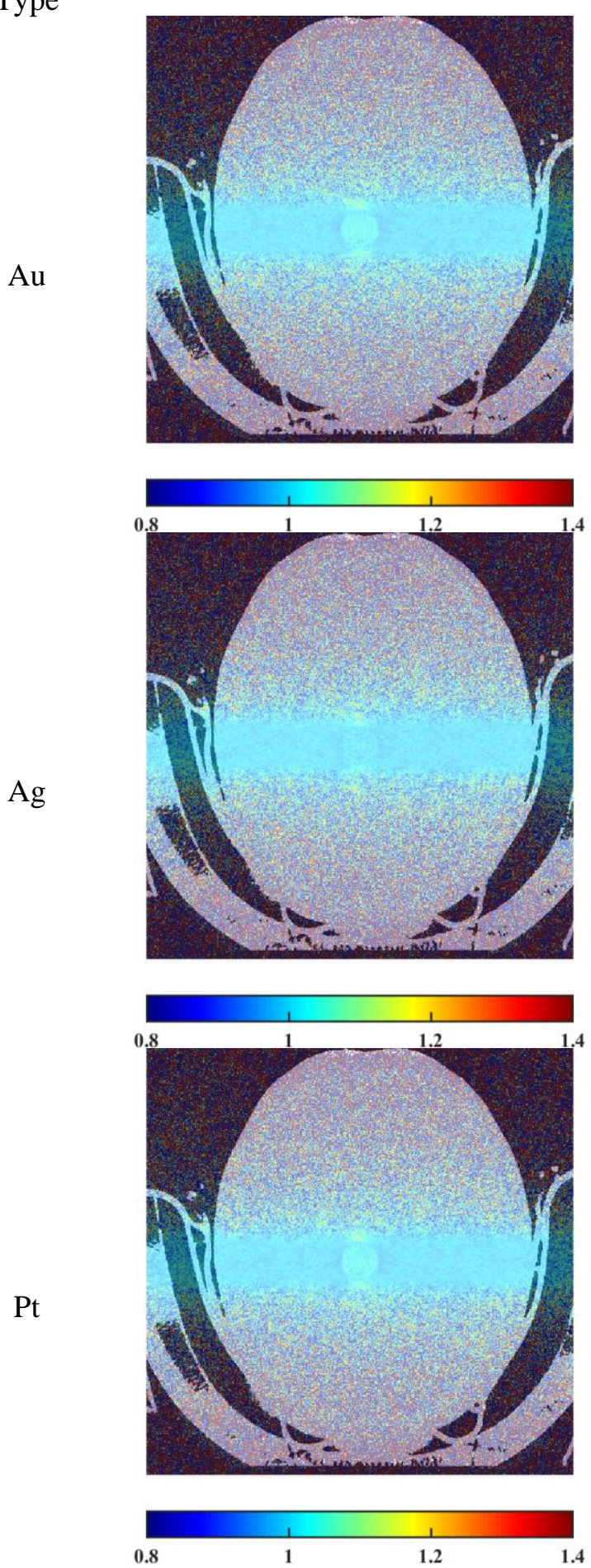

$\mathrm{DEF}_{\text {Pri }}$
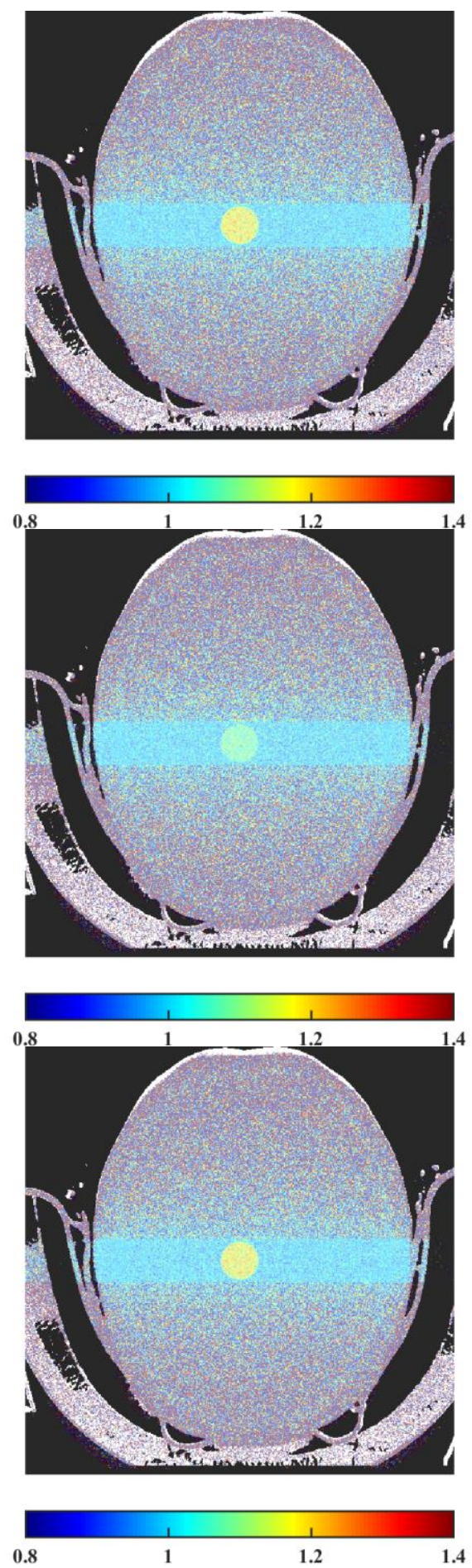

Figure 3. DEF and DEF pri distribution for different NPs types. 
$\mathrm{Bi}$
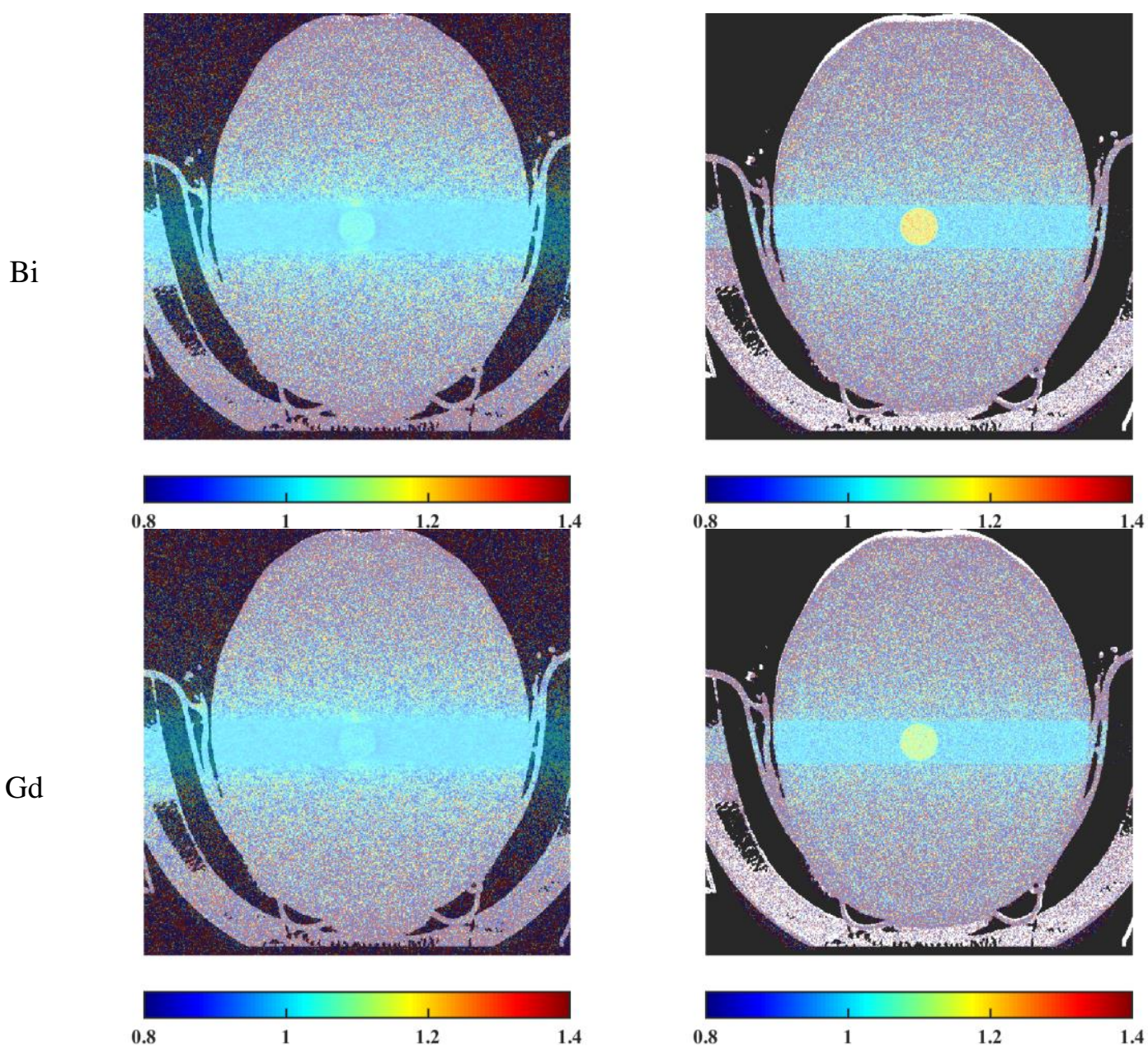

Figure 3 .(continued). DEF and $\mathrm{DEF}_{\text {pri }}$ distribution for different NPs types.

For $\mathrm{Au}$ this increase is from $0 \%$ to $2 \%$, for Pt $0 \%$ to $2 \%$ and $\mathrm{Gd} 0 \%$ to $1 \%$. Au again shows no dose enhancement. There is some localized dose enhancement as shown by the MDEF values, which show increases up to $10 \%$ for $\mathrm{Bi}$ at the highest concentrations.

The reduction in ADEF for the ITV and PTV cases compared to the GTV is to be expected given the surrounding volumes with no NPs embedded. The probability of interaction for the photoelectric effect, Compton Scattering and total interactions with $70 \mathrm{mg} / \mathrm{g}$ NPs concentration in soft tissue are plotted against energy in figures 5, 6 and 7, respectively [31]. Given the typical spectra from clinical linear accelerators [32], the anticipated dose enhancement is likely to be relatively low compared to kilovoltage $\mathrm{x}$-ray energies, as demonstrated in the values calculated in tables 2, 3 and 4 .
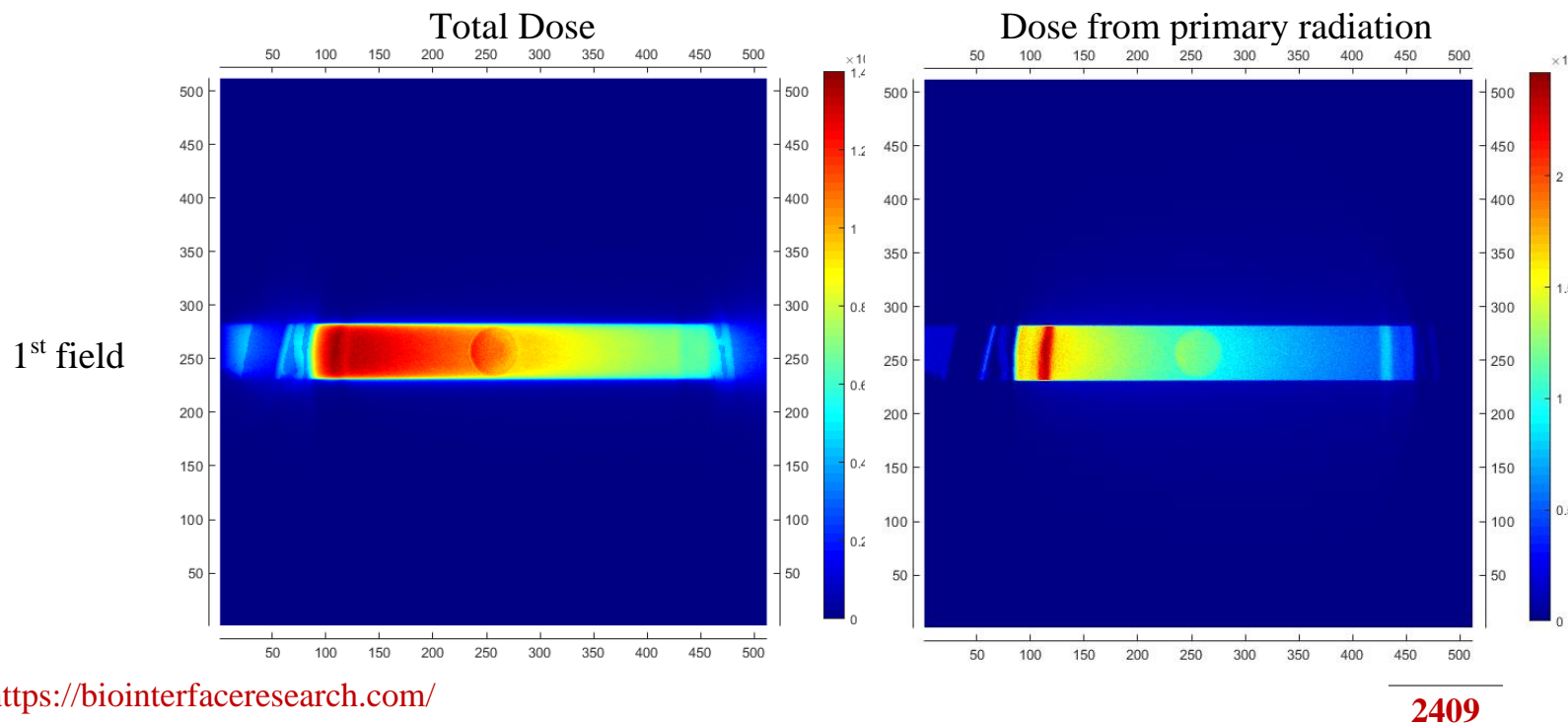


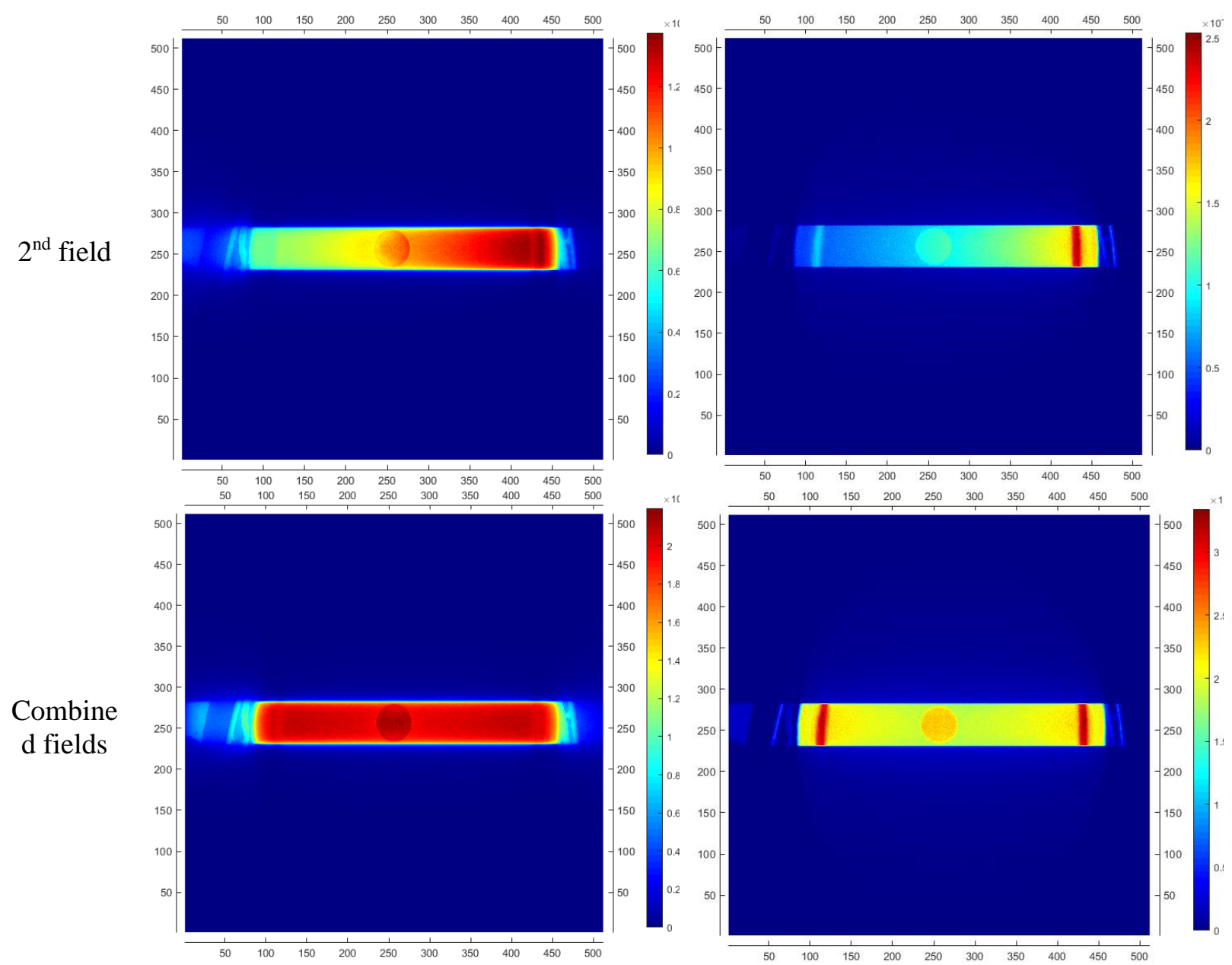

Figure 4. Total and primary dose distributions for $70 \mathrm{mg} / \mathrm{g}$ AuNPs.

Table 2. Dose enhancement in Gross Tumor Volume "GTV" for various nanoparticles type and concentrations.

\begin{tabular}{|c|c|c|c|c|c|c|c|}
\hline $\begin{array}{c}\text { Concentration } \\
(\mathrm{mg} / \mathrm{g})\end{array}$ & NPs Type & MDEFPri & ADEF $_{P r i}$ & MDEF $_{\text {Sec }}$ & $\mathrm{ADEF}_{\text {Sec }}$ & MDEF & ADEF \\
\hline \multirow[t]{5}{*}{70} & $\mathrm{Ag}$ & 1.26 & 1.08 & 1.09 & 0.99 & 1.09 & 1.00 \\
\hline & $\mathrm{Gd}$ & 1.30 & 1.12 & 1.08 & 1.00 & 1.09 & 1.01 \\
\hline & $\mathrm{Pt}$ & 1.32 & 1.16 & 1.09 & 1.01 & 1.09 & 1.02 \\
\hline & $\mathrm{Au}$ & 1.34 & 1.17 & 1.09 & 1.01 & 1.10 & 1.03 \\
\hline & $\mathrm{Bi}$ & 1.34 & 1.18 & 1.09 & 1.01 & 1.10 & 1.03 \\
\hline \multirow[t]{5}{*}{35} & $\mathrm{Ag}$ & 1.26 & 1.05 & 1.08 & 1.00 & 1.09 & 1.00 \\
\hline & $\mathrm{Gd}$ & 1.20 & 1.06 & 1.08 & 1.00 & 1.07 & 1.01 \\
\hline & $\mathrm{Pt}$ & 1.23 & 1.07 & 1.10 & 1.01 & 1.08 & 1.01 \\
\hline & $\mathrm{Au}$ & 1.26 & 1.08 & 1.09 & 1.01 & 1.10 & 1.01 \\
\hline & $\mathrm{Bi}$ & 1.25 & 1.08 & 1.09 & 1.01 & 1.09 & 1.02 \\
\hline \multirow[t]{5}{*}{25} & $\mathrm{Ag}$ & 1.21 & 1.03 & 1.07 & 1.00 & 1.07 & 1.00 \\
\hline & $\mathrm{Gd}$ & 1.19 & 1.04 & 1.08 & 1.00 & 1.07 & 1.00 \\
\hline & $\mathrm{Pt}$ & 1.23 & 1.06 & 1.09 & 1.00 & 1.08 & 1.01 \\
\hline & $\mathrm{Au}$ & 1.22 & 1.06 & 1.09 & 1.00 & 1.10 & 1.01 \\
\hline & $\mathrm{Bi}$ & 1.23 & 1.06 & 1.08 & 1.01 & 1.08 & 1.01 \\
\hline \multirow[t]{5}{*}{15} & $\mathrm{Ag}$ & 1.24 & 1.02 & 1.08 & 1.00 & 1.09 & 1.00 \\
\hline & $\mathrm{Gd}$ & 1.22 & 1.03 & 1.08 & 1.00 & 1.10 & 1.00 \\
\hline & $\mathrm{Pt}$ & 1.19 & 1.04 & 1.08 & 1.00 & 1.08 & 1.00 \\
\hline & $\mathrm{Au}$ & 1.19 & 1.04 & 1.07 & 1.00 & 1.07 & 1.00 \\
\hline & $\mathrm{Bi}$ & 1.2 & 1.04 & 1.07 & 1.00 & 1.08 & 1.01 \\
\hline
\end{tabular}

Table 3. Dose enhancement in Irradiated Tumor Volume "ITV" for various nanoparticles type and concentrations.

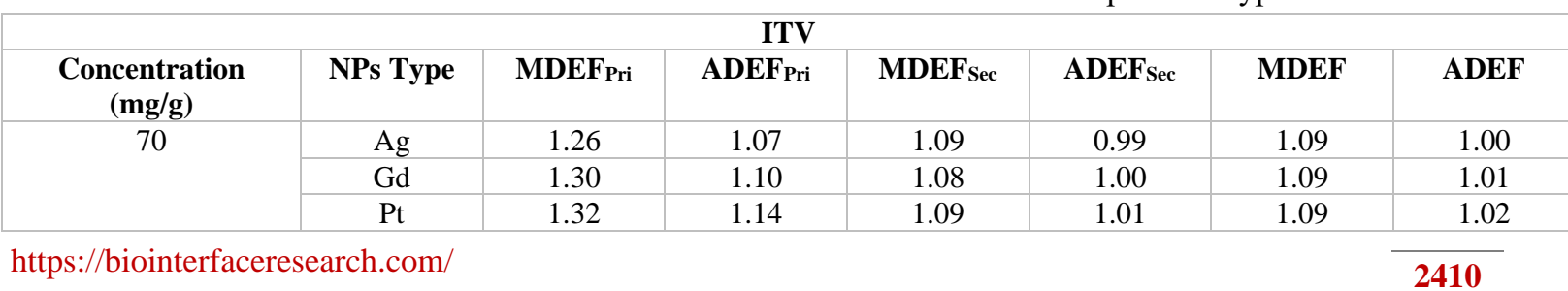




\begin{tabular}{|c|c|c|c|c|c|c|c|}
\hline \multicolumn{8}{|c|}{ ITV } \\
\hline $\begin{array}{c}\text { Concentration } \\
(\mathrm{mg} / \mathrm{g})\end{array}$ & NPs Type & MDEF $_{P r i}$ & ADEF $_{\text {Pri }}$ & MDEF $_{\text {Sec }}$ & $\mathrm{ADEF}_{\text {Sec }}$ & MDEF & ADEF \\
\hline & $\mathrm{Au}$ & 1.34 & 1.15 & 1.09 & 1.01 & 1.10 & 1.02 \\
\hline & $\mathrm{Bi}$ & 1.34 & 1.16 & 1.09 & 1.01 & 1.10 & 1.03 \\
\hline \multirow[t]{5}{*}{35} & $\mathrm{Ag}$ & 1.26 & 1.04 & 1.08 & 0.99 & 1.09 & 1.00 \\
\hline & $\mathrm{Gd}$ & 1.20 & 1.05 & 1.08 & 1.00 & 1.07 & 1.00 \\
\hline & $\mathrm{Pt}$ & 1.23 & 1.07 & 1.08 & 1.00 & 1.08 & 1.01 \\
\hline & $\mathrm{Au}$ & 1.26 & 1.07 & 1.09 & 1.01 & 1.10 & 1.01 \\
\hline & $\mathrm{Bi}$ & 1.25 & 1.07 & 1.08 & 1.01 & 1.09 & 1.01 \\
\hline \multirow[t]{5}{*}{25} & $\mathrm{Ag}$ & 1.21 & 1.02 & 1.07 & 1.00 & 1.07 & 1.00 \\
\hline & $\mathrm{Gd}$ & 1.19 & 1.04 & 1.08 & 1.00 & 1.07 & 1.00 \\
\hline & $\mathrm{Pt}$ & 1.23 & 1.05 & 1.10 & 1.00 & 1.08 & 1.01 \\
\hline & $\mathrm{Au}$ & 1.22 & 1.05 & 1.09 & 1.00 & 1.10 & 1.01 \\
\hline & $\mathrm{Bi}$ & 1.23 & 1.06 & 1.08 & 1.00 & 1.08 & 1.01 \\
\hline \multirow[t]{5}{*}{15} & $\mathrm{Ag}$ & 1.24 & 1.02 & 1.08 & 1.00 & 1.09 & 1.00 \\
\hline & $\mathrm{Gd}$ & 1.22 & 1.03 & 1.09 & 1.00 & 1.1 & 1.00 \\
\hline & $\mathrm{Pt}$ & 1.19 & 1.03 & 1.08 & 1.00 & 1.08 & 1.00 \\
\hline & $\mathrm{Au}$ & 1.19 & 1.03 & 1.07 & 1.00 & 1.07 & 1.00 \\
\hline & $\mathrm{Bi}$ & 1.20 & 1.04 & 1.07 & 1.00 & 1.08 & 1.01 \\
\hline
\end{tabular}

Table 4. Dose enhancement in Planning Target Volume "PTV" for various nanoparticles type and concentrations.

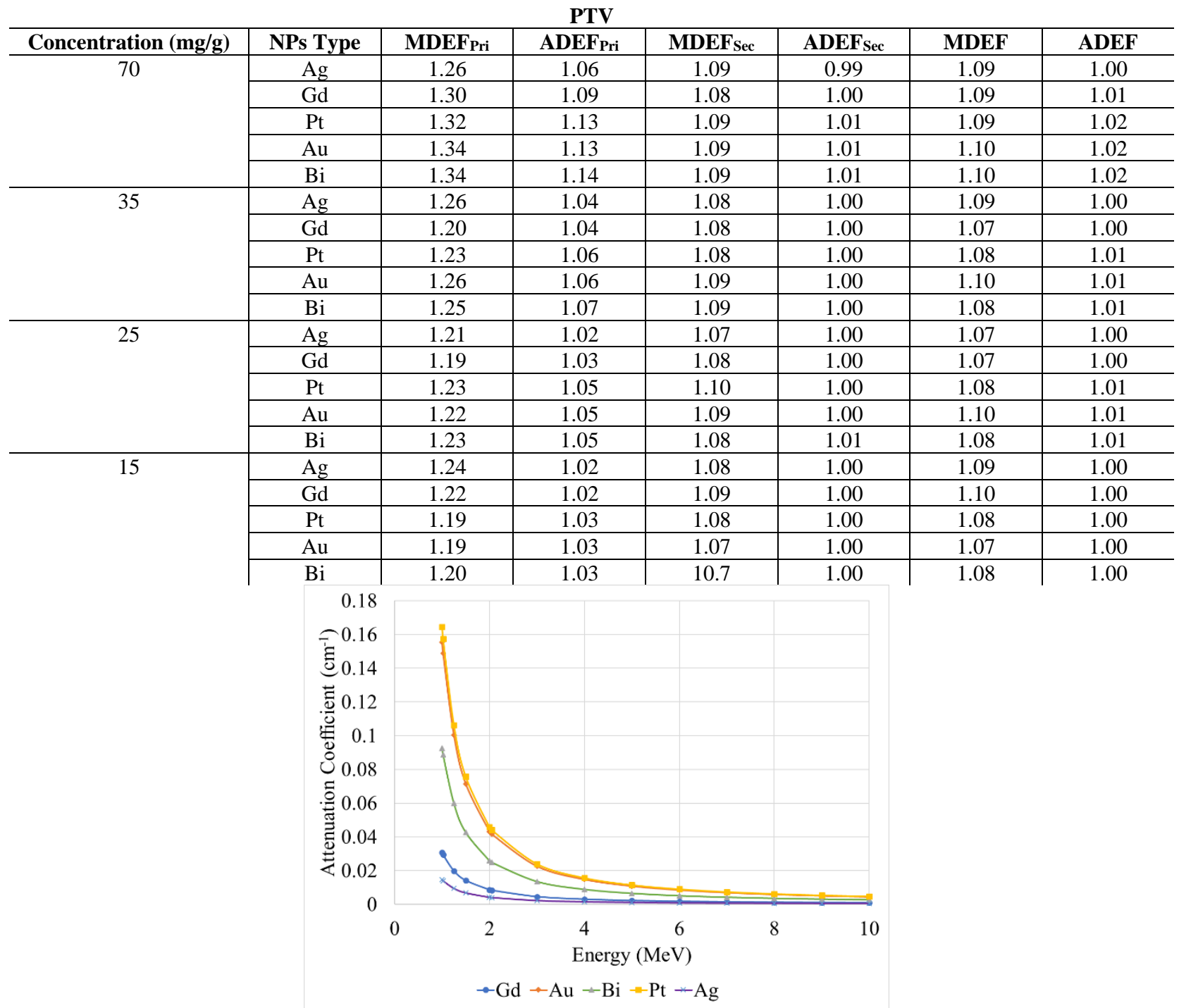

Figure 5. Probability of interaction for photoelectric effect with $70 \mathrm{mg} / \mathrm{g}$ NPs in soft tissue (Source: NIST). 


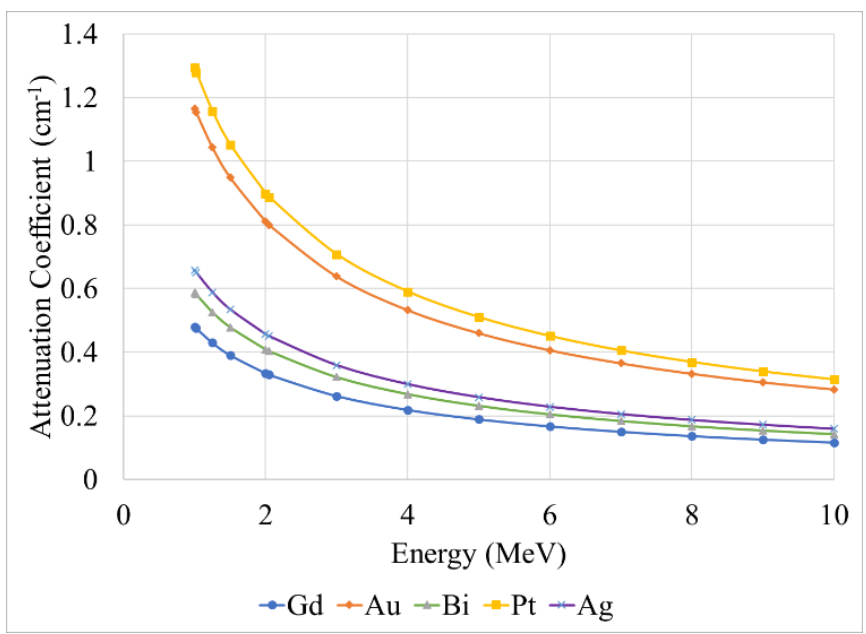

Figure 6. Probability of interaction for Compton scattering with $70 \mathrm{mg} / \mathrm{g}$ NPs in soft tissue (Source: NIST).

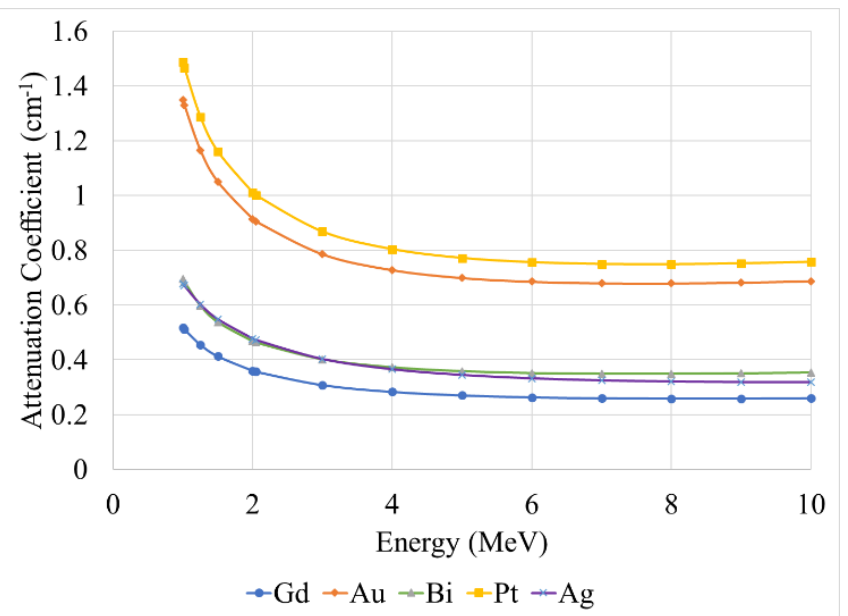

Figure 7. Total probability of interaction with $70 \mathrm{mg} / \mathrm{g}$ NPs in soft tissue (Source: NIST).

\section{Conclusions}

This study has employed a digital phantom created from a CT scan of a patient's head. It has then employed GATE Monte Carlo modeling of a linear accelerator of nominal $6 \mathrm{MV}$ energy to simulate an irradiation geometry for a typical tumor volume situated centrally within the head and neck region. Although simplistic in arrangement, this setup was considered appropriate in order to demonstrate the dose enhancements that may be expected for external beam megavoltage radiation therapy for nanoparticles of different elemental composition and concentration. $\mathrm{Ag}, \mathrm{Gd}$, $\mathrm{Pt}, \mathrm{Au}$ and $\mathrm{Bi}$ were modeled in concentrations varying from $15 \mathrm{mg} \mathrm{NP} /$ gram tissue to $70 \mathrm{mg} \mathrm{NP}$ / gram tissue. The maximum ADEF dose enhancement to the GTV observed was $3 \%$ for $70 \mathrm{mg}$ $\mathrm{NP}$ / gram tissue of Bi. Such a dose enhancement is likely to have limited clinical significance. Therefore, this work demonstrates the limited dose enhancement expected for megavoltage external beam radiotherapy from nanoparticles. Therefore, for NPs to be clinically effective with megavoltage external beam radiotherapy, synergistic chemical or biological effects would also need to play a part.

\section{Funding}

This project was funded by the Deanship of Scientific Research (DSR) at King Abdulaziz University, Jeddah, under grant no. (KEP-17-135-38). The authors, therefore, gratefully acknowledge DSR technical and financial support. 


\section{Acknowledgments}

This project was funded by the Deanship of Scientific Research (DSR) at King Abdulaziz University, Jeddah, under grant no. (KEP-17-135-38). The authors, therefore, gratefully acknowledge DSR technical and financial support.

\section{Conflicts of Interest}

The authors declare no conflict of interest.

\section{References}

1. Delaney, G.; Jacob, S.; Featherstone, C.; Barton, M. The role of radiotherapy in cancer treatment: estimating optimal utilization from a review of evidence-based clinical guidelines. Cancer Interdiscip. Int. J. Am. Cancer Soc. 2005, 104, 1129-1137, https://doi.org/10.1002/cncr.21324.

2. Hall E J and Giaccia AJ Radiobiology for the Radiologist; Wolters Kluwer, Philadelphia, USA, 2018.

3. Jaffray, D.A. Image-guided radiotherapy: From current concept to future perspectives. Nat. Rev. Clin. Oncol. 2012, 9, 688-699, https://doi.org/10.1038/nrclinonc.2012.194.

4. Teoh, M.; Clark, C.H.; Wood, K.; Whitaker, S.; Nisbet, A. Volumetric modulated arc therapy: A review of current literature and clinical use in practice. Br. J. Radiol. 2011, 84, 967-996, https://doi.org/10.1259/bjr/22373346.

5. Kuncic, Z; Lacombe, S. Nanoparticle radio-enhancement: Principles, progress and application to cancer treatment. Phys. Med. Biol. 2018, 63, https://doi.org/10.1088/1361-6560/aa99ce.

6. Her, S.; Jaffray, D.A.; Allen, C. Gold nanoparticles for applications in cancer radiotherapy: Mechanisms and recent advancements. Adv. Drug Deliv. Rev. 2017, 109, 84-101, https://doi.org/10.1016/j.addr.2015.12.012.

7. Haume, K.; Rosa, S.; Grellet, S.; Śmiałek, M.A.; Butterworth, K.T.; Solov’yov, A. V.; Prise, K.M.; Golding, J.; Mason, N.J. Gold nanoparticles for cancer radiotherapy: a review. Cancer Nanotechnol. 2016, 7, 8, https://doi.org/10.1186/s12645-016-0021-X.

8. Butterworth, K.T.; Coulter, J.A.; Jain, S.; Forker, J.; McMahon, S.J.; Schettino, G.; Prise, K.M.; Currell, F.J.; Hirst, D.G. Evaluation of cytotoxicity and radiation enhancement using $1.9 \mathrm{~nm}$ gold particles: potential application for cancer therapy. Nanotechnology 2010, 21, 295101, https://doi.org/10.1088/09574484/21/29/295101.

9. Jain, S.; Coulter, J.A.; Butterworth, K.T.; Hounsell, A.R.; McMahon, S.J.; Hyland, W.B.; Muir, M.F.; Dickson, G.R.; Prise, K.M.; Currell, F.J.; et al. Gold nanoparticle cellular uptake, toxicity and radiosensitisation in hypoxic conditions. Radiother. Oncol. 2014, 110, 342-347, https://doi.org/10.1016/j.radonc.2013.12.013.

10. Podgorsak, E.B. Radiation Physics for Medical Physicists; Biological and Medical Physics, Biomedical Engineering; Springer Berlin Heidelberg: Berlin, Heidelberg, 2010; ISBN 978-3-642-00874-0, https://doi.org/10.1007/978-3-642-00875-7.

11. Farahani, S.; Riyahi Alam, N.; Haghgoo, S.; Shirazi, A.; Geraily, G.; Gorji, E.; Kavousi, N. The effect of bismuth nanoparticles in kilovoltage and megavoltage radiation therapy using magnetic resonance imaging polymer gel dosimetry. Radiat. Phys. Chem. 2020, 170, 108573, https://doi.org/10.1016/j.radphyschem.2019.108573.

12. Nakayama, M.; Akasaka, H.; Geso, M.; Morita, K.; Yada, R.; Uehara, K.; Sasaki, R. Utilisation of the chemiluminescence method to measure the radiation dose enhancement caused by gold nanoparticles: A phantom-based study. Radiat. Meas. 2020, 134, 106317, https://doi.org/10.1016/j.radmeas.2020.106317.

13. Kazmi, F.; Vallis, K.A.; Vellayappan, B.A.; Bandla, A.; Yukun, D.; Carlisle, R. Megavoltage Radiosensitization of Gold Nanoparticles on a Glioblastoma Cancer Cell Line Using a Clinical Platform. Int. J. Mol. Sci. 2020, 21, 429, https://doi.org/10.3390/ijms21020429.

14. Ricketts, K.; Ahmad, R.; Beaton, L.; Cousins, B.; Critchley, K.; Davies, M.; Evans, S.; Fenuyi, I.; Gavriilidis, A.; Harmer, Q.J.; et al. Recommendations for clinical translation of nanoparticle-enhanced radiotherapy. $B r$. J. Radiol. 2018, 91, 20180325, https://doi.org/10.1259/bjr.20180325.

15. Yang, C.; Bromma, K.; Sung, W.; Schuemann, J.; Chithrani, D. Determining the Radiation Enhancement Effects of Gold Nanoparticles in Cells in a Combined Treatment with Cisplatin and Radiation at Therapeutic Megavoltage Energies. Cancers (Basel). 2018, 10, 150, https://doi.org/10.3390/cancers10050150.

16. Bonvalot, S.; Rutkowski, P.L.; Thariat, J.; Carrère, S.; Ducassou, A.; Sunyach, M.-P.; Agoston, P.; Hong, A.; Mervoyer, A.; Rastrelli, M.; et al. NBTXR3, a first-in-class radioenhancer hafnium oxide nanoparticle, plus radiotherapy versus radiotherapy alone in patients with locally advanced soft-tissue sarcoma (Act.In.Sarc): a multicentre, phase 2-3, randomised, controlled trial. Lancet Oncol. 2019, 20, 1148-1159, https://doi.org/10.1016/S1470-2045(19)30326-2.

17. Hahn, M.B.; Zutta Villate, J.M. Combined cell and nanoparticle models for TOPAS to study radiation dose 
enhancement in cell organelles. Sci. Rep. 2021, 11, 6721, https://doi.org/10.1038/s41598-021-85964-2.

18. Abdollahi, B.B.; Malekzadeh, R.; Azar, F.P.; Salehnia, F.; Naseri, A.R.; Ghorbani, M.; Hamishehkar, H.; Farajollahi, A.R. Main approaches to enhance radiosensitization in cancer cells by nanoparticles: A systematic review. Adv. Pharm. Bull. 2021, 11, 212-223, https://doi.org/10.34172/apb.2021.025.

19. Retif, P.; Pinel, S.; Toussaint, M.; Frochot, C.; Chouikrat, R.; Bastogne, T.; Barberi-Heyob, M. Nanoparticles for Radiation Therapy Enhancement: the Key Parameters. Theranostics 2015, 5, https://doi.org/10.7150/thno.11642..

20. Kumar Sharma, P.; Malviya, R. Toxicity and application of nano-silver in multi-drug resistant therapy. Letters in Applied Nanobioscience 2020, 9, 824-829, https://doi.org/10.33263/LIANBS91.824829.

21. Radhakrishnan, M.C.; Peter, N. Biological Properties of Silver Nanoparticles from $\beta$ ( 1-3 ) Glucan Isolated from the Edible Mushroom Pleurotus. 2021, 10, 2096-2106, https://doi.org/10.33263/LIANBS102.20962106..

22. Vilotte, F.; Jumeau, R.; Bourhis, J. High Z nanoparticles and radiotherapy: a critical view. Lancet Oncol. 2019, 20, e557, https://doi.org/10.1016/S1470-2045(19)30579-0.

23. Gray, T.; Bassiri, N.; David, S.; Patel, D.Y.; Stathakis, S.; Kirby, N.; Mayer, K.M. A detailed experimental and Monte Carlo analysis of gold nanoparticle dose enhancement using $6 \mathrm{MV}$ and $18 \mathrm{MV}$ external beam energies in a macroscopic scale. Appl. Radiat. Isot. 2021, 171, https://doi.org/109638.10.1016/j.apradiso.2021.109638.

24. Taha, E.; Djouider, F.; Banoqitah, E. Monte Carlo simulations for dose enhancement in cancer treatment using bismuth oxide nanoparticles implanted in brain soft tissue. Australas. Phys. Eng. Sci. Med. 2018, 41, 363-370, https://doi.org/10.1007/s13246-018-0633-z.

25. Mohammadzadeh, M.; Ghiasi, H. Monte Carlo characterization of the gold nanoparticles dose enhancement and estimation of the physical interactions weight in dose enhancement mechanism. J. Polish Soc. Med. Phys. 2020, 26, https://doi.org/10.2478/pjmpe-2020-0026.

26. Vlastou, E.; Diamantopoulos, S.; Efstathopoulos, E.P. Monte Carlo studies in Gold Nanoparticles enhanced radiotherapy: The impact of modelled parameters in dose enhancement. Phys. Medica 2020, 80, 57-64, https://doi.org/10.1016/j.ejmp.2020.09.022.

27. Li, W.B.; Belchior, A.; Beuve, M.; Chen, Y.Z.; Di Maria, S.; Friedland, W.; Gervais, B.; Heide, B.; Hocine, N.; Ipatov, A.; et al. Intercomparison of dose enhancement ratio and secondary electron spectra for gold nanoparticles irradiated by X-rays calculated using multiple Monte Carlo simulation codes. Phys. Medica 2020, 69, 147-163, https://doi.org/10.1016/j.ejmp.2019.12.011.

28. Jan, S.; Santin, G.; Strul, D.; Staelens, S.; Assié, K.; Autret, D.; Avner, S.; Barbier, R.; Bardiès, M.; Bloomfield, P.M.; et al. GATE -Geant4 Application for Tomographic Emission: a simulation toolkit for PET and SPECT. Phys Med Biol. Phys Med Biol 2004, 49, 4543-4561, https://doi.org/10.1088/00319155/49/19/007.

29. Kwatra, D.; Venugopal, A.; Anant, S. Nanoparticles in radiation therapy: a summary of various approaches to enhance radiosensitization in cancer. Transl. Cancer Res. 2013, 2.

30. Prescribing, Recording, and Reporting Photon-Beam Intensity-Modulated Radiation Therapy (IMRT). $J$. ICRU 2010, 10, 1-3, https://doi.org/10.1093/jicru_ndq002.

31. Berger, M.J.; Hubbell, J.H.; Seltzer, S.M.; Chang, J.; Coursey, J.S.; Sukumar, R.; Zucker, D.S.; Olsen, K. XCOM: Photon Cross Section Database (version 1.5). Natl. Inst. Stand. Technol. Gaithersburg, MD 2010, https://dx.doi.org/10.18434/T48G6X .

32. Nisbet, A.; Weatherburn, H.; Fenwick, J.D.; McVey, G. Spectral reconstruction of clinical megavoltage photon beams and the implications of spectral determination on the dosimetry of such beams. Phys. Med. Biol. 1998, 43, 1507-1521, https://doi.org/10.1088/0031-9155/43/6/010. 